\title{
EXTRA PLEURAL SOLITARY FIBROUS TUMOR: A REPORT OF TWO CASES
}

\author{
G. Meenakumari ${ }^{1}$, N. Sharmila Thilagavathy², M. S. Lalitha ${ }^{3}$
}

\section{HOW TO CITE THIS ARTICLE:}

G. Meenakumari, N. Sharmila Thilagavathy, M. S. Lalitha. "Extra Pleural Solitary Fibrous Tumor: A Report of Two Cases". Journal of Evolution of Medical and Dental Sciences 2014; Vol. 3, Issue 67, December 04;

Page: 14524-14530, DOI: $10.14260 /$ jemds/2014/3948

\begin{abstract}
Solitary fibrous tumor (SFT) belongs to a group of mesenchymal tumors, first described as a primary spindle cell tumor of the pleura in 1931. Recently, SFT has been reported in various locations with no relation to serosal surface. We describe two such cases in unusual sites of orbit and nasal cavity. Histopathologically, the tumors had a disorganized or "patternless" arrangement of spindle cells in a collagenous background and prominent vascular channels of varying sizes. Immunohistochemically both tumours showed CD 34 positivity. The two patients had benign clinical course with limited follow-up. SFT should be included in the differential diagnosis of spindle cell tumors arising in the nasal cavity and orbit.
\end{abstract}

KEYWORDS: Solitary fibrous tumor, orbit, nasal cavity.

INTRODUCTION: Since Solitary fibrous tumor was first introduced by Klemperer and Rabin in 1931 in the pleura as a type of mesothelioma,[1] It has been described under various names such as localized fibrous mesothelioma, submesothelioma, subpleural fibroma or subserosal fibroma. Even though it has recently been reported that SFT can develop in various sites other than the pleura such as the peritoneum, mediastinum, pericardium, lung, liver, pancreas, thyroid gland, parapharyngeal space, nasopharynx, larynx, salivary gland etc, occurrence in the nasal cavity, paranasal sinus and orbit is extremely rare.[2,3] We report two cases of extrapleural Solitary fibrous tumour one arising from the orbit and other in the nasal cavity.

\section{CASES REPORT:}

CASE 1: 60-year-old man presented with reduced vision of left eye for 2 years and protrusion of the left eyeball for 1 month. On examination left eye showed eccentric proptosis, nonpulsatile, noncompressible and absence of extraocular movements. Computed tomography and MRI demonstrated a well-defined mass measuring $2.3 \times 2.3 \times 2 \mathrm{~cm}$ in intraconal region of left eye occupying superomedial compartment extending inferiorly showing immediate enhancement on IV contrast and medial rectus muscle hypertrophy. No bony erosion or deformity. Suggestive of Solitary fibrous tumour.

We received excised soft tissue mass measuring $2.5 \times 2 \times 2 \mathrm{~cm}$. Cut section was greyish white and firm in consistency. Histopathological examination revealed a well circumscribed cellular tumor composed of spindle shaped cells arranged in sheets. Intervening stag hornlike vascular spaces, pseudovascular spaces and floret giant cells were seen. Tumour cells showed immunopositivity for CD 34.

CASE 2: 35 years old female presented with nasal obstruction of 6 months duration. Diagnostic nasal endoscopy was performed which showed a mass in nasal cavity. CT scan showed homogenous opacity in sphenoid sinus extending into the nasal cavity 


\section{CASE REPORT}

We received excised mass measuring 1 x 1 x $0.5 \mathrm{~cm}$. Cut section was grayish white and firm in consistency. Histopathology of the mass showed spindle shaped tumour cells arranged in fascicles and sheets. Intervening stroma showed vascular spaces. Tumour cells were CD 34 positive.

DISCUSSION: Solitary fibrous tumours were first described in visceral pleura in 1931.Since then they have been described in extrapleural sites such as peritoneum, mediastinum, pericardium, lung, liver, upper respiratory tract, nasopharynx, paranasal sinus, meninges, thyroid, soft tissue orbit and other sites. Neoplasms considered as separate entities including hemangiopericytoma are presently encompassed as Solitary fibrous tumours. ${ }^{[4]}$

Clinical symptoms relate to location of tumour. Tumours of the nasal cavity or paranasal sinus usually occur after 30 years of age, commonly in woman and often present with nasal obstruction including the present case. Orbital SFT commonly present with gradual unilateral progressive proptosis and mass effect.

Histologically Solitary fibrous tumours are formed by plump spindle cells arranged in patternless fashion in a collagenous background. Typically there are hyper and hypocellular areas with prominent vascularity that results in a haemangiopericytoma like pattern. A Giant cell rich form though can occur in diverse locations was originally identified in the orbital region. ${ }^{[5,6]}$ It exhibits all the features of classic SFT along with pseudo vascular spaces lined by multinucleated stromal giant cell as in our case of orbital SFT.

SFT show immuno positivity for CD34.[7] This is of diagnostic usefulness as other spindle cell tumours like neurofibroma, schwanomma, benign fibrous histiocytoma, fibrosarcoma show absent or weak staining for CD34. They also express CD 99, Bcl 2 and vimentin and are negative or weakly positive for muscle specific action, desmin, S100, Factor VIII related antigen and neurofilament. ${ }^{[8]}$ Solitary fibrous tumours have been reported to be malignant in $13-24 \%$ of cases. Features associated with malignancy includes increased cellularity, pleomorphism and mitosis ( $>4 / 10 \mathrm{hpf}$ ). ${ }^{[9,10]}$ Malignant SFTs have high risk of recurrence and metastasis. SFT with benign histologic features require surgery and follow up and those with malignant areas require adjuvant therapy.

CONCLUSION; Solitary fibrous tumours though initially described in parietal pleura can occur in many extrapleural sites including orbit and nasal cavity. Neoplasms such as hemangiopericytoma which were considered as separate entities are presently encompassed as solitary fibrous tumours. Solitary fibrous tumour should be included in the differential diagnosis of spindle cell tumours of nasal cavity and orbit. Immunohistochemistry is an important adjunct in determining the diagnosis. Long term follow up is necessary because of the possibility of recurrence after excision. 


\section{CASE REPORT}

Figure 1: CT scan image showing intraconal left side soft tissue dense mass measuring $2.3 \times 2 \times 1.3 \mathrm{~cm}$ extending along the medial rectus with intense homogenous enhancement.

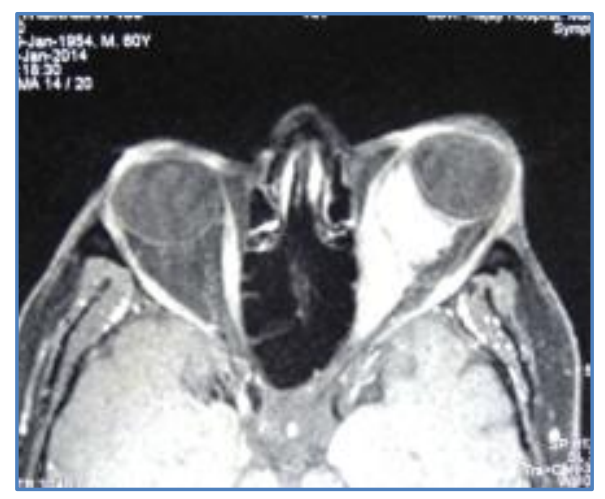

Fig. 1

Figure 2: MRI Scan demonstrating $2.3 \times 2.7 \times 2.3 \mathrm{~cm}$ mass in intraconal region of left eye occupying superomedial compartment and extending inferiorly.

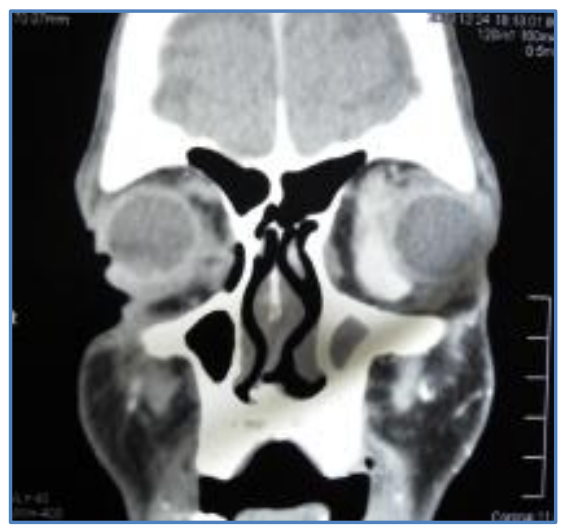

Fig. 2

Figure 3: Orbital SFT - grayish white tumor measuring $2.5 \times 2 \times 2 \mathrm{~cm}$.

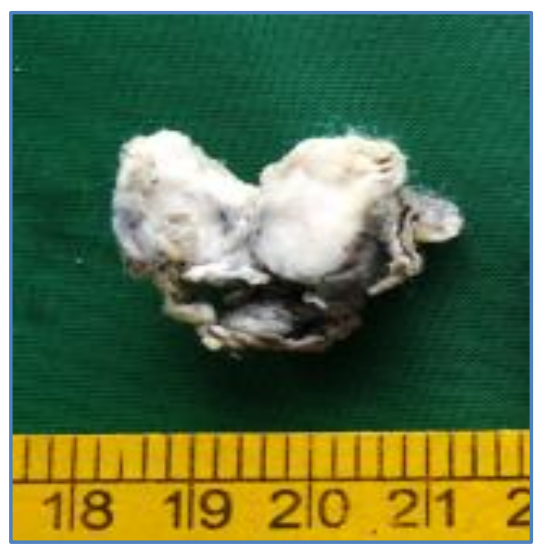

Fig. 3 


\section{CASE REPORT}

Figure 4: Orbital SFT - The tumor cells are spindle shaped, arranged in sheets with intervening staghorn like vascular spaces. (10x).

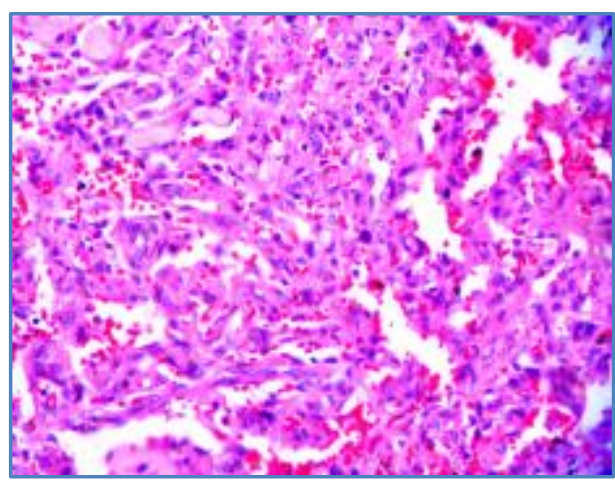

Fig. 4

Figure 5: Orbital SFT - vascular spaces and giant cells (10x).

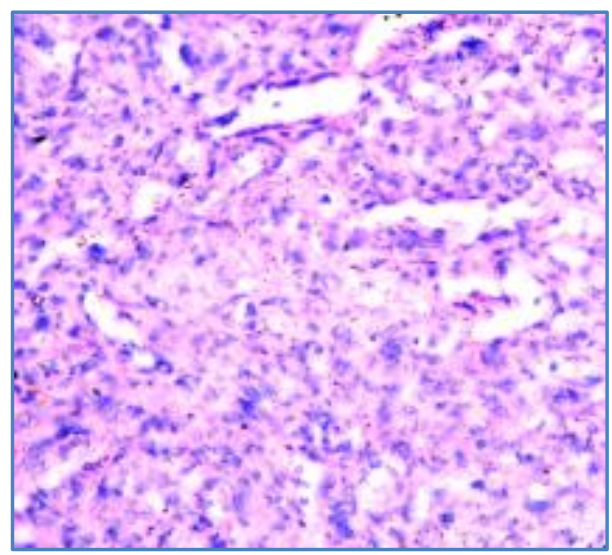

Fig. 5

Figure 6: Orbital SFT - tumor cells show CD 34 positivity.

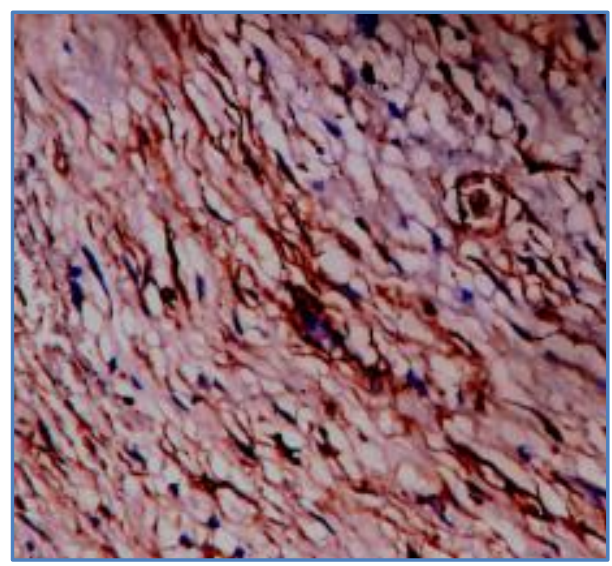

Fig. 6 


\section{CASE REPORT}

Figure 7: Nasal cavity SFT - showing lining pseudostratified columnar epithelium and underlying tumor. $(4 \mathrm{x})$

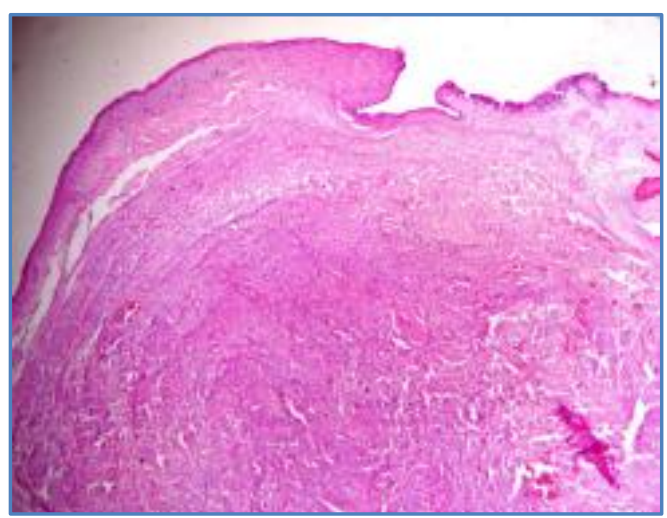

Fig. 7

Figure 8: Nasal cavity SFT - showing tumor cells and vascular spaces (10 x).

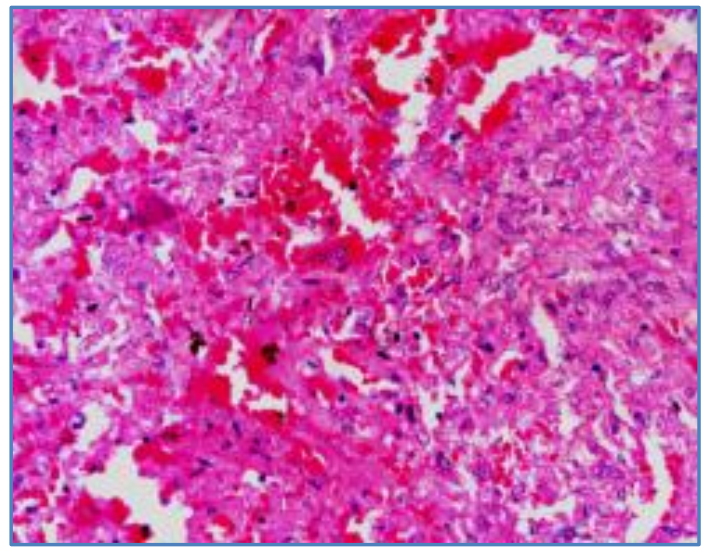

Fig. 8

Figure 9: Nasal cavity SFT - showing tumor cells arranged in a patternless fashion $(10 \mathrm{x})$.

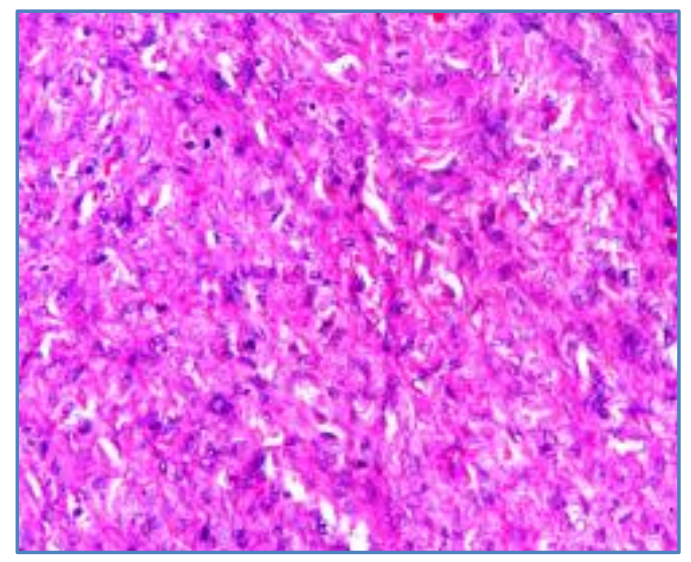

Fig. 9 


\section{CASE REPORT}

Figure 10: Nasal cavity SFT tumor cells showing CD 34 positivity.

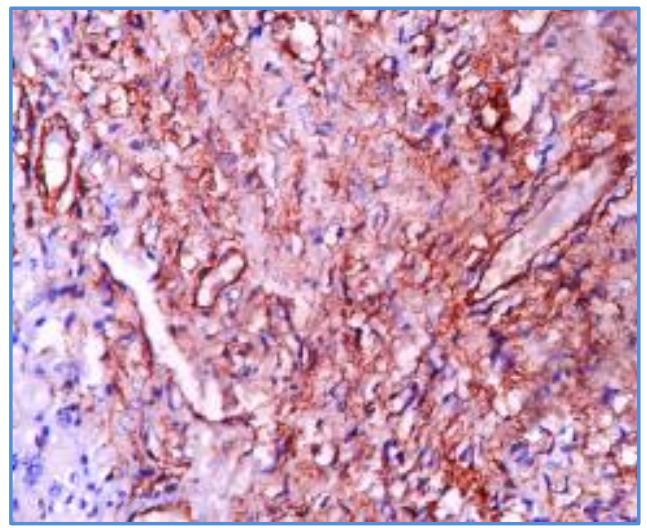

Fig. 10

\section{REFERENCES:}

1. Klemperer P, Rabin CB. Primary neoplasms of the pleura: Report of five cases. Arch Pathol 1931; 11: 38.

2. Brunnerman RB, Rojy, Ordonez N G et al. Extrapleural Solitary fibrous tumour: a clinicopathologic study of 24 cases. Mod Pathol 1999; 12: 1034.

3. Fukunaga M, Naganuma H, Nikaido T, et al. Extrathoracic Solitary fibrous tumours: a report of seven cases. Mod Pathol 1997; 10: 443.

4. Gengler C, Guillou L. Solitary fibrous tumour and hemangiopericytoma: evolution of a concept. Histopathology 2006; 48: 63.

5. Dei TOSAP, Seregard S, Calonje E, etal. Giant cell angiofibroma: A distinctive orbital tumour in adults. Am J Surg Pathol 1995; 19: 1286.

6. Guillov L.Gebhard S, Coindre JM. Orbital and extraorbital giant cell angiofibroma: a giant cell rich variant of Solitary fibrous tumour? clinicopathologic and immunohistochemical analysis of a series in favour of a unifying concept.AM J Surg Pathol 2000; 24;971.

7. Van de Rijin M, Lombard CM, Rouse RV. Expression of CD 34 by Solitary fibrous tumour of pleura, mediastinum and lungs. Am J Surg Pathol 1994; 18: 814.

8. Hanau CA, Miettinem M. Solitary fibrous tumour: histological and immunohistochemical spectrum of benign and malignant variants presenting at different sites.Human Pathol 1995; 26: 440.

9. Hasegawa T, Matsumo Y, Shimoda T, etal. Extrathoracic Solitary fibrous tumours: their histological variability and potentially aggressive behavior. Hum Pathol 1999; 30: 1464.

10. Young RH, Clement PB, Mc Caughey WT. Solitary fibrous tumours and potentially aggressive behavior. Hum Pathol 1999; 114: 493. 


\section{CASE REPORT}

\section{AUTHORS:}

1. G. Meenakumari

2. N. Sharmila Thilagavathy

3. M. S. Lalitha

\section{PARTICULARS OF CONTRIBUTORS:}

1. Professor, Department of Pathology, Madurai Medical College.

2. Professor, Department of Pathology, Madurai Medical College.

3. Post Graduate Student, Department of Pathology, Madurai Medical College.

\section{NAME ADDRESS EMAIL ID OF THE} CORRESPONDING AUTHOR:

Dr. G. Meenakumari, \#23, Surya Nagar,

First Street,

K. Pudur, Maduari.

Email: meenakumariilango1971@gmail.com

Date of Submission: 22/11/2014.

Date of Peer Review: 24/11/2014.

Date of Acceptance: 01/12/2014.

Date of Publishing: 04/12/2014. 